Running head: INFORMANT INDEPENDENCE AND TRUST IN CONSENSUS

Thinking for themselves? The effect of informant independence on children's endorsement of testimony from a consensus

\author{
Shiri Einav \\ University Of Nottingham
}

Accepted date: $22 / 08 / 17$

Article in Press

To Appear in Social Development

Acknowledgements. I would like to thank Leona Jacob, Mark Carey, Laura Outhwaite, Giovanni Sala, and Zara Ali for help with stimuli preparation, data collection and coding. I thank Liz Robinson for helpful comments on an earlier version of the manuscript. Please address correspondence to: Shiri Einav, School of Psychology, University of Nottingham, Nottingham NG2 7RD, UK. Email: shiri.einav@nottingham.ac.uk 


\begin{abstract}
Testimony agreement across a number of people can be a reassuring sign of a claim's reliability. However, reliability may be undermined if informants do not respond independently. In this case, social consensus may be a result of indiscriminate copying or conformity and does not necessarily reflect shared knowledge or opinion. We examined children's emerging sensitivity to consensus independence by testing whether it affected their judgements in a social learning context. Children ages 5, 6 and 8-9 years $(N=92)$, and 20 adults for comparison, received conflicting testimony about an unfamiliar country from two consensual groups of informants: An independent group who responded privately and a nonindependent group who had access to each other's answers. We found increasing levels of trust in independent consensus with age. Adults and 8-9 year-olds preferred to accept the claims of the independent consensus, whereas 5-year-olds favored the claims of the nonindependent consensus and 6-year-olds were mixed. Although previous work has shown that children trust a consensus over a lone dissenter as young as 2 years, the developmental shift in this study indicates that children's reasoning about the nature of consensus and what makes it reliable continues to develop throughout middle childhood.
\end{abstract}

Keywords: testimony; selective trust; consensus; conformity; knowledge 


\section{Thinking for themselves? The effect of informant independence on children's endorsement of testimony from a consensus}

As adults, we regularly utilize the knowledge of others to gain information about the world that we have not acquired directly. Although we are aware that people's beliefs may not always be accurate, when a number of sources agree on a particular point we feel more confident that their view is correct and can be trusted (Cialdini \& Goldstein, 2004; Claidière \& Whiten, 2012; Kelley, 1973). The consistency of testimony across different individuals means that people from multiple perspectives, who have individual learning experiences, perceptions and memories, nonetheless think the same. Following the consensus is likely to be a relatively safe strategy because, as Eaves and Shafto (2012) noted, the probability of unreliable or unhelpful informants converging on the same inaccurate claim is low (see also, Haun, Van Leeuwen, \& Edelson, 2013). However, this is not necessarily true in all cases where people's testimony is in agreement. A crucial factor is the independence of informants from one another. Independence can refer to a number of factors, including whether or not individuals are personally connected in some way, and whether people's claims all originate from the same or separate sources (e.g., the same book vs. different books). Here, we focus on informants' independence in terms of their awareness of each other's testimony at the time of responding.

Humans are highly susceptible to social influence when making decisions in a social context, whether for informational or normative reasons. When individuals are aware of the decisions of others, they are prone toward "herd behavior" (Banerjee, 1992, p. 798), abandoning their own opinion to converge with others (e.g., Schneider \& Watkins, 1996), especially when uncertainty is high (e.g., Allan, Midjord, Martin, \& Gabbert, 2012). In such cases, they may believe that others are better informed than they are (Lorenz, Rauhut, Schweitzer, \& Helbing, 2011). Moreover, a perceived social pressure to conform may lead 
people to publicly agree with others despite privately disagreeing in order to avoid censure or embarrassment (Asch, 1956; Deutsch \& Gerard, 1955; but see Bond \& Smith, 1996 for contradictory findings). Consequently, although it is possible that when individuals make decisions publicly they converge on the same answer independently, there are no guarantees. The challenge posed by a non-independent consensus is that observers cannot be certain to what extent members were influenced by each other's judgments. Compared to an independent consensus then, it provides a more questionable epistemic marker as consistency across individuals does not necessarily validate their responses as correct.

The current research aimed to examine how sensitivity to consensus independence, and the impact of this factor on testimony reliability, emerges in development. In recent years, substantial work has examined children's developing ability to engage in epistemic vigilance (Sperber et al., 2010) and attempted to elucidate their criteria for acceptance or rejection of testimony from others (for reviews see Harris, 2012; Mills, 2013; Robinson \& Einav, 2014). Researchers have investigated not only how children evaluate testimony from individual informants, but also whether they attend to the number of people who endorse a claim. Findings indicate that the tendency to trust a consensus arises early on. Preschoolers are more likely to endorse an informant's claim if it receives explicit assent (displayed via nods and smiles) rather than dissent (displayed via head shakes and frowns) from two bystanders (Fusaro \& Harris, 2008). Moreover, children do not require agreement to be explicitly marked by verbal or non-verbal cues; consistent testimony across informants suffices. For example, children as young as 2 years are more likely to act on a novel apparatus to locate a reward in accordance with the same behavior displayed by three peers than an alternative behavior shown an equal number of times by an individual (Haun, Rekers, \& Tomasello, 2012). Preschoolers more frequently trust the claims of three consensual informants than those of a dissenting individual when learning to identify referents for novel 
labels (Corriveau, Fusaro, \& Harris, 2009). In addition, 3-6 year-olds are more likely to imitate faithfully a novel action sequence that is demonstrated identically by two models rather than twice by a single model (Herrmann, Legare, Harris, \& Whitehouse, 2013). It is not currently clear to what extent the consensus effect demonstrated in these studies arises because children deem a consensual view as more reliable than the belief of one individual, rather than being a result of social motives (e.g., to align oneself with the group).

Importantly, however, mounting evidence suggests that children can reason about the reliability of the consensus in a given situation rather than blindly follow the crowd. When the epistemic credentials of the majority and the dissenter are unknown (as in the above studies), children trust the consensus, but when consensus reliability is undermined by other epistemic cues, they endorse the dissenter. Specifically, plausibility or conventionality of testimony (Bernard, Harris, Terrier, \& Clément, 2015; Guerrero, Cascado, Sausa, \& Enesco, 2017; Schillaci \& Kelemen, 2014), informants’ expertise (Boseovski, Marble, \& Hughes, 2017), access to knowledge (Einav, 2014), previous accuracy (Bernard, Proust, \& Clément, 2015), and previous success (Wilks, Collier-Baker, \& Nielsen, 2015) all trump the consensus cue, although the evidence is mixed regarding the age at which children recognize when it is best not to trust the majority. In several studies, this was seen from 4 years, whereas in others not before 5 or 6 years of age. These mixed findings may be due to a number of methodological differences across tasks that have yet to be disentangled systematically (e.g., type of epistemic cue pitted against the consensus; variations in the way the protagonists were presented (live actors, videotaped actors, puppets, or characters in vignettes); children's prior knowledge; content domain). Nevertheless, age-related changes may indicate that younger children follow the consensus for social reasons, and therefore do so regardless of its epistemic reliability, whereas older children follow the consensus only in situations where it retains its epistemic value (see Bernard, Proust et al., 2015). 
By age 6 then, children reason about the reliability of a consensus, but it is an open question whether they view independence as a relevant factor. Notably, in the above studies the informants appeared to provide their testimony independently, either acting simultaneously (e.g., via pointing), thereby preventing copying, or successively but separately. (For exceptions where individuals were privy to previous informants' testimony, see Schillachi \& Kelemen, 2014; Wilks et al., 2015.) However, the epistemic implications of this aspect of consensus were not discussed. The most relevant work to date from $\mathrm{Hu}$, Whalen, Buchsbaum, Griffiths and Xu (2015), found that 3-5 year-olds placed more trust in a consensus where all group members had direct perceptual access to the novel information (box contents) versus a consensus where only one member had access and the remaining members explicitly based their opinion on that informant's testimony (i.e., "[S]he said this [toy/snack] was better, so I think this [toy/snack] is better"). Accordingly, individuals' responses were independent in one consensus group and non-independent in the other. However, the two groups also differed with respect to the number of individuals who had perceptual access. Consequently, the study is informative in showing that children deem consensus based on visual access as more reliable than consensus based on hearsay but does not address to what extent independence alone influences children's evaluation of testimony reliability. Moreover, consensual responses in the hearsay group were explicitly marked as contingent on the first informant's testimony, whereas we were interested in whether children spontaneously infer the possibility of copying among individuals who are aware of each other's answers.

In sum, although young children's tendency to endorse a consensus over a dissenter has been examined in a number of studies, much less is known about development after the preschool years and involving more complex scenarios where children must reason not simply about the number of people who agree on a claim but about the nature of the 
agreement. In the present study, we aimed to address this gap in the literature. More generally, we sought to extend previous work on children's critical thinking that has largely focused on evaluation of individual informants who provide their testimony in the absence of a social context. By contrast, we wished to shed some light on children's developing ability to consider how a person's testimony may be influenced by the testimony of others and how that social context impacts the reliability of what they say.

We presented participants with conflicting testimony from two groups, each composed of three individuals whose responses were always in agreement. In one group, the informants answered privately, whereas in the second group, they answered publicly. Our intuition, which we checked in this study, was that adults would distinguish between the two types of consensus and place more trust in the former. Our primary aim was to examine agerelated changes: We asked whether 5-, 6- and 8-9 year-olds differ in the way they consider the reliability of the two consensus groups. We tested 5- and 6-year-olds in light of the findings that at this age children can scrutinize the reliability of a consensus group on the basis of various competence cues (Bernard, Harris et al., 2015; Einav, 2014) and extended the age range to 8-9 years because of concurrent development in children's understanding of how social motivation may influence individuals' behavior (for review see, Mills, 2013), which we considered relevant to our task.

Specifically, there is evidence to suggest that children learn about self-presentation (the desire to shape others' beliefs about the self) gradually and only start to attribute selfpresentation motives to explain why others' behavior may deviate from their actual thoughts or feelings from about the age of 8 years. For example, 6-year-olds have difficulty identifying self-presentation motives (e.g., wanting to avoid being seen as stupid or a coward) to explain falsely expressed emotions (Banerjee, 2000, 2002; Banerjee \& Yuill, 1999). In addition, children's ability to attribute embarrassment to others increases between 6 and 11 years 
(Banerjee, 2002). To the best of our knowledge, the question of when children explain others' or their own behavior in terms of conformity has not been addressed empirically. Studies have shown that children themselves are susceptible to conformity from the age of 4 years (Corriveau \& Harris, 2010; Corriveau, Kim, Song, \& Harris, 2013; Haun \& Tomasello, 2011). However, the literature cited above suggests that the capacity for recognizing conformity in others may not emerge for several years. If children fail to consider potential social motives for copying (e.g., to avoid embarrassment or to seek approval), they may initially take non-independent agreement at face value (i.e., all informants think this way) rather than recognize that there may be a mismatch between what the informants believe and what they say. We therefore anticipated that 5-6 year-olds would be less likely to question the reliability of the non-independent consensus compared to 8-9 year-olds.

Furthermore, the younger children may not recognize that although the independent consensus members must each come up with the answer on their own, the non-independent individuals' answers may all stem from the mind of the informant who answers first, reducing the reliability of this consensus to a single person's testimony. This type of reasoning requires an ability to infer that the second and third informants may themselves be ignorant or uncertain (mental state) despite providing an answer (behavior). Young children are sensitive to verbal and non-verbal cues of uncertainty in others and moderate their trust in informants' testimony on the basis of this information (e.g., Birch, Akmal, \& Frampton, 2010; Jaswal \& Malone, 2007; Sabbagh \& Baldwin, 2001). Further, 4-5 year-olds are less likely to trust an informant who in the past explicitly relied upon a third party for providing accurate information rather than generating the answers on his own (Einav \& Robinson, 2011). However, in the current study, the informants did not give any indication of uncertainty so the possibility that the second and third informants may not have known the answer had to be inferred. Indeed, we specifically chose to tell participants that the 
informants in this group were told to look at each other's answers so that their looking would not be interpreted as a sign of uncertainty (or as cheating) to avoid confounding these factors with non-independence.

In the current study, the testimony related to information regarding an unfamiliar country. Participants were told that the informants had taken part in a lesson about the country to clarify that all of them had acquired the information in the same way. We chose to ask about knowledge of an unfamiliar country as a way of presenting children with information that a) they would have no prior knowledge about, and b) the informants only recently learned and could feasibly get correct (i.e., remember accurate information from their lesson), incorrect (e.g., misremember) or be unsure about (e.g., be unable to remember). Similar to the established selective trust paradigm (e.g., Koenig \& Harris, 2005), participants could choose to endorse one of the groups' suggestions or an alternative third option on a series of trials. Following the test trials, participants were asked explicitly to judge which group they believed the most and to justify their choice.

\section{Method}

\section{Participants}

Participants were 92 children whose parents provided written informed consent. There were twenty eight 5-year-olds $\left(M_{\text {age }}=5 ; 7\right.$, range 5;0 to 5;11, 13 females $)$, thirty two 6year-olds $\left(M_{\text {age }}=6 ; 6\right.$, range $6 ; 0$ to $6 ; 11,15$ females $)$ and thirty two $8-9$ year-olds $\left(M_{\text {age }}=\right.$ $8 ; 11$, range $8 ; 2$ to $9 ; 9,17$ females). All children were native English speakers and predominantly white middle class, although a range of socioeconomic backgrounds and ethnicities were represented. Children were recruited from two local schools and from Summer Scientist Week, an outreach initiative run by the University, where local children visit the University and take part in a range of psychology studies. 


\section{Materials and Design}

Two groups of three female actors (ages 18-21) formed the informant groups: Independent Consensus (IC) and Non-independent Consensus (NIC). Every child was presented with the testimony of both groups on every trial. These were shown through video clips on a laptop using PowerPoint. The videos were positioned in the center of the screen; one below the other (the position of the IC and NIC were counterbalanced across participants). The informants in both groups sat at a table with the same three pictures laid out identically in front of them on every trial. On test trials, the IC were separated from each other by barrier walls, which were absent for the NIC (see Figure 1).

Each vignette began with the voice of an off-screen speaker, ostensibly the informants" teacher, asking them the question for that trial (e.g., "Which is the right flag for this country?") The informants always responded in the same order, left to right, when their name was called out (e.g., "Lucy!") Each named informant looked at her three pictures and selected one of them, holding it up in the air and looking directly at the camera before placing it on the table and removing the other pictures. The key difference in the way the IC and NIC responded is as follows: When each informant responded in the IC, the remaining informants looked straight ahead. In contrast, when the first NIC informant picked her chosen picture, the other two informants leaned over and looked at her answer (see Figure 1). Similarly, when the middle informant picked her chosen picture, the informant on her right, leaned over and looked at her answer. Finally, the second and third informants glanced at the previous informant's selection while they reached for the same picture to emphasize that their choice was not independent.

Each group picked one of three picture cards that answered a question in the stimulus book about a fictional country called Markovia. The three actors in each group always chose the same picture; however, the responses were different across the two informant groups 
(e.g., 3 football cards vs. 3 basketball cards). Videos were counterbalanced in two ways across participants; in terms of the female actors who made up the IC and NIC, and the responses given by the two groups. This resulted in four videos that were counterbalanced equally across children per age group. The stimulus book about Markovia consisted of five pages (one example and four experimental trials), each with a question, background illustrations relating to the question topic (e.g., a plate for the food trial; flag bunting for the flag trial) and a blank space for the child's picture answer. Question topics included housing (example trial), flag design, food, scenery and sport. These were always presented in the same order. The three corresponding picture cards were also presented live to the child participant.

\section{Procedure}

Children were tested individually in a quiet area near their classroom or at the University. The experimenter (E) began by introducing the child to the "faraway country" of Markovia and the book about it, indicating the gaps and explaining it would be the child's job to fill them in with the correct pictures. The example trial served to introduce children to the task. E presented the child with three picture cards for a question about the type of housing in Markovia. E explained that she recently visited the country and so knew a bit about it. She then picked one of the three cards and demonstrated positioning it in the book.

In the four experimental trials children were required to select pictures and fill in the book themselves but were told that they could have some help, "Now it's going to be your job to fill in the other pages with the right pictures. But before you do that, I'm going to let you see what these girls on the computer think about Markovia [E showed stills of both groups and told the participant what each girl was called]. They've all had a lesson about this country. The teacher in the video is going to ask them questions about it. So, you'll be able to 
see what they pick and that should help you decide which pictures should go in the book, OK?"

Next, still images were shown of the two groups with their set of pictures ready for the first trial, and the barriers set up between the IC informants. E explained that the IC group could not see each other's responses because of the dividing blocks between them. (Children were then familiarized with an identical divider and experienced not being able to see how many fingers E held up behind the divider to ensure they understood its opaqueness.) Similarly, E explained that the NIC group did not have any barriers between them and that they were told to look at each other's answers before they reply; a demonstration of leaning forward to look was given: "Now, the girls in this group [point at NIC group], were told to look at each other's answers before they reply, so you'll see them lean over and have a look (demonstrate lean forward). The girls in this group [point at IC group] can't look at each other's answers before they reply because of these barriers [point at barriers]. Here is a barrier just like theirs, let's put it between us. Can you see how many fingers I put up behind this barrier? That's right, you can't see through it. They can't see each other's answers either."

At the start of each trial, the child was presented with the question in the stimulus book and the three relevant picture cards. For example, "this page says: the sport most people like to play there is... and then there's a blank, so you need to decide which of these three sports is most popular in Markovia, football, basketball or cricket." The position in which the three pictures (IC choice, NIC choice, distractor) were placed in front of the child (top, middle or bottom) varied randomly across participants and across trials. The two informant videos were then presented, "now let's watch what the girls in the videos picked and then you can decide". On each trial, E played the IC and NIC videos one after the other saying, "now 
let's see what these girls picked". The order in which the testimony of the IC and NIC were presented alternated across trials.

After watching both videos, children were reminded of the actors' decisions with a still shot of each group with their chosen picture cards in front of them (see Figure 1, right). Children were then instructed to choose the correct picture from their selection to go in the book. Each response was coded as either following the IC, the NIC or picking the distractor. Neutral feedback was given. This procedure was repeated for three more trials.

To examine children's explicit group evaluation and their justifications, children were presented with still shots of the groups following the test trials and asked, "which group of girls did you believe the most? Why is that?" Finally, there was a memory check of group independence, “which group looked at each other's answers? Which didn't look?” (order counterbalanced). All children correctly responded to the memory check.

\section{Coding and Reliability}

Justifications in response to the explicit judgment question fell into five categories: 1) Believed IC more because of their independent answering or because NIC were not independent (e.g., "Because they [IC] couldn't be influenced by each other - had to stick to what they thought", "Because the others were copying each other"); 2) Believed NIC more because of their non-independence (e.g., "Because they didn’t have the blocks", "because they can see each other's pictures"); 3) Content-based, (e.g., "Their answers looked right”, "because they picked football”); 4) The appearance of the informants or liking them more (e.g., "They looked a bit serious”, “looked more clever”); 5) residual, (e.g., "Don’t know”, "I think so" or no response). An independent rater coded half of the responses from each age group, and interrater agreement was $90 \%$ (Cohen's $\kappa=.85)$. Disagreements were resolved by discussion.

\section{Adult Group}


Twenty undergraduate university students (10 females, range: $20-22$ years, $M_{\text {age }}=$ 21.1 years) volunteered to take part in an adapted version of the experiment. Participants were tested individually and viewed the same stimuli as the child participants but these were self-administered on a laptop using PsychoPy software (Peirce, 2007). All the instructions were presented in writing on screen and the participants entered their forced-choice responses via the keyboard. For the open-ended justification question, responses were made verbally and noted down by the experimenter.

\section{Results}

\section{Adult Data}

First, we checked our intuition that adults tend to treat an independent consensus as more reliable than a non-independent consensus. All but three adults endorsed the IC response on every trial and only one participant never did so. Moreover, 95\% participants stated that they believed the IC more and justified this with reference to their independent responses (e.g., "They came to the same answer separately so they are more likely to be right"; "The others [NIC] were all influenced by the first person, they [IC] all chose the same so small probability of it happening by chance.")

\section{Children's Endorsement Trials}

For each child, we counted the number of times children chose the IC, NIC and distractor responses across the four trials. Figure 2 shows the mean percentage for each possible choice as a function of age group. In the analyses that follow we first examined agerelated differences in children's endorsement of the IC. We then ran planned comparisons of the mean for each possible choice (IC, NIC, or distractor) against chance level. Although only two of the three pictures were selected by the informant groups in each trial, $25 \%$ children selected the choice that was not indicated by either group on at least one trial of four. (Five 5-year-olds chose the distractor on 1 trial, two on 2 trials, and one on all 4 trials; one 6- 
year-olds chose the distractor on 1 trial, six on 2 trials, and two on 3 trials; three 8-9 year-olds chose the distractor on 1 trial, one on 2 trials, and two on 4 trials.) Accordingly, chance was calculated to be 1.33 of a possible total of 4 (probability of success per trial $(0.33) \times 4)$. This criterion has been used in previous selective trust studies where participants were given a choice of three responses but only two were indicated by the informants (see Bernard, Proust, et al., 2015; Corriveau et al., 2009). However, we also ran a second comparison to directly test whether participants had a systematic preference for endorsing one group over the other.

Preliminary analyses found no significant effects involving gender or video version therefore these two factors were not included in the following analyses. A one-way betweengroups analysis of variance (ANOVA) on the number of times participants picked the same picture as the IC found a significant main effect of age, $F(2,89)=6.98, p=.002, \eta p^{2}=.14$. Posthoc tests using Bonferroni correction found that 8-9 year-olds picked the picture endorsed by the IC significantly more often $(M=2.44, S D=1.39)$ than the 5-year-olds $(M$ $=1.50, S D=.75)$ and the 6 -year-olds $(M=1.63, S D=.94), p=.003$ and $p=.01$, respectively. The two younger groups did not differ from each other. (Due to non-normality of the data and heterogeneity of variance, we also ran non-parametric Kruskal-Wallis analysis and follow-up Mann-Whitney comparisons on the number of times children endorsed the IC choice. These produced an identical pattern of results to the ones reported above.)

Planned comparisons against a chance score of 1.33 on the number of times children picked the same as the IC found that only 8-9 year-olds did so at rates higher than chance, $t(31)=4.51, p<.001, d=.80$, whereas 5-year-olds and 6-year-olds responded at chance: 5year-olds, $t(27)=1.21, p=.24, \mathrm{~ns}, d=.23$, and 6-year-olds: $t(31)=1.77, p=.09, \mathrm{~ns}, d=.32$. In contrast, the two younger age groups picked the same as the NIC at rates higher than chance: 5 -year-olds, $M=2.04, S D=1.10, t(27)=3.38, p=.002, d=.65$, and 6-year-olds, $M$ $=1.78, S D=1.04, t(31)=2.46, p=.02, d=.43$. The older group picked the answers given by 
the NIC at rates no different to chance, $M=1.16, S D=1.17, t(31)<-1, p=.41, \mathrm{~ns}, d=.15$. All groups picked the distractor at rates lower than would be expected by chance $(p \mathrm{~s}<.001)$.

Next, we examined whether participants showed a systematic preference for one group over the other on those trials in which they endorsed the choice of one of the groups. (Note that the 3 participants who chose the distractor across all 4 trials were not included in this analysis.) Children were categorized into displaying one of three strategies: 'IC endorsers' sided with the IC on more trials than they sided with the NIC, 'NIC endorsers' sided the NIC more than the IC, and 'Mixed' endorsed the groups an equal number of times (See Table 1).

Chi-square analysis revealed that the pattern of responses across age groups was different, $\chi^{2}(4, N=89)=26.07, p<.001$, Cramer's $\mathrm{V}=.38$ with an apparent shift from NIC endorsement as the most frequent strategy among 5-year-olds to a more frequent mixed response among 6-year-olds, to IC endorsement as the prevalent strategy among 8-9 yearolds. Additional analyses in each age group compared i) the number of children who showed a preference for one group (either IC or NIC) versus the number of children who were mixed, and ii) the frequencies of the two consensus endorsement strategies. The findings confirmed that 8-9 year-olds were more likely to show a preference than be mixed, $\chi^{2}(1, N=30)=$ $19.20, p<.001$, and among those who showed a preference, IC endorsement was significantly more frequent than NIC endorsement, $\chi^{2}(1, N=27)=6.26, p=.012$. Six-yearolds were just as likely to be mixed as they were to be systematic, $\chi^{2}(1, N=32)=0$, and among those who showed a preference, the number of IC endorsers was comparable with the number of NIC endorsers, $\chi^{2}(1, N=16)=1, p=.32$. Finally, 5-year-olds were not significantly systematic as a group, $\chi^{2}(1, N=27)=3.00, p=.083$, but among those who showed a preference, NIC endorsement was significantly more frequent than IC endorsement, $\chi^{2}(1, N=18)=5.56, p=.018$. 


\section{Children's Explicit Judgments and Justifications}

For the analysis of children's response to the explicit judgment question, "Who did you believe the most?" and the justifications analysis below, we excluded two 5-year-olds, four 6-year-olds and two 8-9 year-olds who gave a 'both', 'neither' or 'don't know' response despite a further prompt to choose one group. Chi-square goodness of fit tests revealed that the two younger groups' judgments were not systematic: 5 -year-olds, IC: $42 \%$, NIC: $58 \%, \chi^{2}$ $(1, N=26)=0.62, p=.43$ and 6 year-olds, IC: $46 \%$, NIC: $54 \%, \chi^{2}(1, N=28)=0.14, p=$ .71. In contrast, 8-9 year-olds chose the IC significantly more often than the NIC, IC: $70 \%$, NIC: $30 \%, \chi^{2}(1, N=30)=4.80, p=.03$.

Justifications for the explicit judgment question were coded according to the coding scheme outlined above. Figure 3 presents the frequency distributions of the various justification types, by age group. Focusing first on justifications for picking the IC because of their independence or the non-independence of the NIC (e.g., "They're (IC) not actually looking at each other, thinking for themselves, other three (NIC) could have been wrong, all looked at each other") versus all other responses combined, Chi-square tests with Yates' Continuity Correction revealed that 8-9 year-olds were much more likely to mention independence (60\% participants) than 5-year-olds ( $8 \%$ participants), $\chi^{2}(1, N=56)=14.40, p$ $<.001$, Phi $=.54$, and 6-year-olds $(25 \%$ participants $), \chi^{2}(1, N=58)=5.88, p=.02$, Phi $=.35$. There was no difference between 5- and 6- year-olds. The most frequent alternative response for the youngest children was failure to give a relevant justification $(38 \%)$; however, it is worth noting that a minority (19\%) justified picking the NIC because of their nonindependence (e.g., "They could see each other's pictures"; "they know because they copied"). This response was also given by $25 \% 6$-year-olds and $17 \% 8-9$ year-olds. Finally, few participants cited the informants' appearance/behavior or having a preference for either 
of the groups as a justification, suggesting the groups were well matched and that participants did not view one as generally more positive or likeable than the other.

\section{Discussion}

We examined children's epistemic trust in consensual testimony that arose via independent versus non-independent means. This study extends previous work on children's selective learning from a consensus versus a dissenter to examine how sensitivity to the nature of agreement between individuals - rather than simply the presence of it - emerges in development. As predicted, we found increasing levels of trust in independent consensus with age. Like the adults, 8-9 year-olds were more likely to accept the claims provided by the group whose responses were independent over the group who could look at each other's answers. In addition, children at this age were more likely to pick the IC as the group they believed the most, with the majority of children citing independence as their justification. In contrast, 5-year-olds favored the NIC's claims in their endorsements although they were not systematic when explicitly asked who they believed the most. Six-year-olds were more mixed in their responses; like the 5-year-olds they endorsed the NIC (but not the IC) at rates above chance but their most frequent response was to endorse both groups to the same extent, and children were almost equally split in their explicit judgments.

Our findings suggest that there is a developmental shift in children's reasoning about consensus independence. Interestingly, 5-year-olds' endorsements were influenced by this cue but in the opposite direction to 8-9 year-olds and adults, whereas 6-year-olds appeared to be transitioning between the two positions. Thus, children are sensitive to the relevance of whether or not individuals forming a consensus have access to each other's testimony from a young age, and they may interpret this information differently across middle childhood.

Why did the younger children prefer to follow the advice of the NIC? We explore three possible explanations: First, children might have viewed the fact that the NIC were able 
to see each other's answers as giving them an advantage over the IC, as if this extra informational access served to increase their authority. Indeed, some children justified their decision for believing the NIC in this way (e.g., "Because they could look").

Second, they may have perceived the two groups differently, assuming the NIC to be friends but regarding the IC simply as three individuals. Perhaps the barriers introduced a psychological distance between the IC that was absent from the NIC. If so, the younger children may have endorsed the NIC 'friends' because they viewed them as a collective with whom they wished to affiliate more than the IC. Previous work suggests that 5-year-olds' trust in the consensus may, under certain circumstances, be driven by social rather than epistemic reasons, in contrast to older children (Bernard, Proust, et al., 2015). An interesting question is whether this social motivation is particularly compelling if the consensus members are perceived as friends. We think this explanation is unlikely, however, for two reasons. First, participants did not mention friendship in their justifications for trusting the NIC. Second, both groups of informants were shown sitting side-by-side (i.e., without the barriers in place for the IC) when they were initially introduced to participants. We therefore think it more plausible that participants would have perceived the groups similarly and accepted that each group was given a different set of instructions regarding whether or not they could look at each other's answers, akin to real-life class situations where classmates are split into groups that are given different task instructions. Nonetheless, it would be useful to introduce the two groups explicitly as friends (or alternatively as strangers) in further work to test this account.

The third explanation is that children might have interpreted the non-independent consensus as a sign of active agreement between the informants that was lacking among the independent group. That is, by deciding to agree with informant 1's responses, informants 2 and 3 provided supportive evidence that she was right. Just as children trust testimony that 
receives explicit bystander assent, as displayed through nods and smiles (Fusaro \& Harris, 2008), they may view the act of copying as a sign of the copiers' approval, which bolsters the reliability of the testimony for them. One 6-year-old expressed this reasoning when justifying why she believed the NIC the most, "because if they're copying, it might be the right thing." From a philosophical standpoint, this can be seen as a rational response. According to Lackey (2013), copiers' own background beliefs or assessment of the original source's credibility should enable them to monitor the testimony critically, so their decision to agree is in itself an informative reliability marker. However, in reality copying does not necessarily constitute critical and deliberate endorsement of this kind. Goldman (2001) argued that, "When Y is a non-discriminating reflector of $\mathrm{X}, \mathrm{Y}$ 's opinion has no extra evidential worth $[\ldots]$ above and beyond X's opinion. [...] The same point applies no matter how many putative experts share an initial expert's opinion" (pp. 101-102). The epistemic value of non-independent consensus, therefore, hinges on the copiers' reasons for agreeing with the original source. If children do not question these, they have no cause to distrust such agreement but rather may view it as more compelling than a consensus that arises independently.

Thus, it may be that the age-related changes found in the current study relate to inferences children make about the knowledge and motives of the copiers. For example, the findings may reflect growing skepticism about whether or not the second and third NIC informants knew the answer rather than relying on the knowledge of the first informant. Although children as young as 3 years are sensitive to others' verbal and non-verbal cues of ignorance or uncertainty (Birch et al. 2010; Sabbagh \& Baldwin, 2001), the ability to infer the possibility of these mental states in the absence of overt markers is likely to emerge later. Until such skepticism arises, children may believe that all members of the NIC know the answers and are therefore no different than members of the IC who must each come up with the answers on their own. In contrast, older children will recognize that the testimony of the 
NIC potentially stems from one source who might be wrong. Future research could examine this by asking children to rate the knowledge of each of the informants that make up an independent and non-independent consensus, respectively. Younger children would be expected to attribute equal knowledge status across members of both groups whereas older children would be expected to show a difference between groups, attributing equal knowledge status to all of the IC members but greater knowledge to the first NIC member in comparison to the second and third informants.

Age-related changes may also reflect children's growing appreciation of alternative psychological reasons, other than shared knowledge, that could underlie non-independent agreement, which have to be learned and inferred. Specifically, children needed to recognize that informants in the NIC might have gone along with the previously stated answers, even if they privately disagreed, to avoid being the odd one out or looking stupid. This account is consistent with the finding that around 8 years of age children develop an understanding of how intentions and motivations, particularly self-presentation, influence behavior and may lead to a mismatch between people's thoughts and actions (Banerjee, 2000, 2002; Banerjee \& Yuill, 1999; Mills, 2013). Before this development children might not even consider the possibility that someone might change his or her answer after hearing someone else's reply. One way to test this account in future research would be to ask children about the beliefs of the second and third NIC informants. Older children should agree that these informants (particularly the last responder) might think that the correct answer is in fact different from what they stated, whereas younger ones would deny that.

Interestingly, our developmental shift mirrors similar shifts in middle childhood, where certain cues that elicit skepticism among older children and adults have been found to produce the reverse effect among young children (see Heyman, 2014). For example, 9-10 year-olds judge a neutral judge as being more likely to be fair than a judge with a positive 
personal connection to contestants, whereas 5-6 year-olds show the opposite pattern, preferring the connected judge to the neutral judge (Mills \& Keil, 2008). Children who are 10-11 years treat self-reports about people's evaluative traits (e.g., intelligence or honesty) with skepticism, whereas 6-7 year-olds claim self-reports to be credible sources of information (Heyman \& Legare, 2005). Further, 8-year-olds recognize that claims that are consistent rather than inconsistent with someone's self-interests are less trustworthy, but 5-6 year-olds show the opposite pattern (Mills \& Keil, 2005). Our findings add to these by suggesting that children may first view non-independence as a positive cue for trust before they realize that it can negatively impact the reliability of testimony.

Although age-related changes were found, there were also substantial individual differences within each age group. What distinguishes the children who preferred to trust the IC from those who preferred the NIC and from those who did not differentiate between the two? It seems plausible that differences in both the ability and motivation to engage in mentalizing play a role. In our task, participants were faced with two groups of informants who on the surface agreed with each other. It was only through considering how the informants' mental states might differ between the independent and non-independent conditions that the two groups could be distinguished appropriately. As Miller (2012) suggests, there may be individual differences "such that some people routinely search for mentalistic underpinnings to behaviour whereas others require strong prods before moving beyond surface-level explanations" (p. 201). Previous studies of selective trust with preschoolers have found links with performance on theory of mind tasks (e.g., BrosseauLiard, Penney, \& Poulin-Dubois, 2015; Fusaro \& Harris, 2008; Lucas, Lewis, Pala, Wong, \& Berridge, 2013; but see also Pasquini, Corriveau, Koenig, \& Harris, 2007). Moreover, individual differences in skepticism found among 6-9 year-olds have been linked to advanced social cognition skills, specifically interpretive theory of mind (Mills \& Elashi, 2014). Aside 
from this, very little is known about the factors that help some children to be better than others at evaluating social sources of information; this remains a key question for further work.

It will also be important to build on the current study by examining children's responses to consensus independence in other social learning contexts. Here, we focused on fact-learning, in line with the majority of research on selective trust. However, the results could differ for other types of testimony such as subjective or value-laden information about objects, other people, or a course of action (see Boseovski \& Lee, 2008; Boseovski et al., 2017), and in more complex situations involving testimony about different kinds of procedures and practices.

In sum, our findings extend previous work on children's selective learning by indicating that although the tendency to place trust in a consensus arises as early as 2 years (Haun et al., 2012); children's reasoning about what it is that makes a consensus reliable continues to develop over a protracted period. Across 5-9 years of age children displayed a growing realization that independent agreement - where individuals' responses cannot be influenced by the responses of others - is more reliable than non-independent agreement. The youngest children were more likely to endorse the claims of the non-independent consensus indicating that they interpret testimony independence differently than older children. These findings highlight the need for further research into children's developing understanding about other social factors that have a bearing on the reliability of group views. For example, social diversity (differences in race, gender, age, political leanings or ideologies) has been argued to be an important condition for consensus reliability, where agreement is considered more reliable when it arises among a heterogeneous rather than homogenous group of individuals (Miller, 2013). It remains a fascinating open question whether children would be sensitive to differences in the compositions of groups, when situated in a child-relevant 
context, and how views about the epistemic implications of this dimension might change across development. 


\section{References}

Allan, K., Midjord, J. P., Martin, D., \& Gabbert, F. (2012). Memory conformity and the perceived accuracy of self versus other. Memory \& Cognition, 40, 280-286. doi:10.3758/s13421-011-0141-9

Asch, S. E. (1956). Studies of independence and conformity: I. A minority of one against a unanimous majority. Psychological Monographs: General and Applied, 70, 1-70. doi: $10.1037 / \mathrm{h} 0093718$

Banerjee, A. (1992). A simple model of herd behavior. The Quarterly Journal of Economics, 107, 797-817. doi:10.2307/2118364

Banerjee, R. (2000). The development of an understanding of modesty. British Journal of Developmental Psychology, 18, 499-517. doi:10.1348/026151000165823

Banerjee, R. (2002). Children's understanding of self-presentational behaviour: Links with mental-state reasoning and the attribution of embarrassment. Merrill-Palmer Quarterly, 48, 378-404. doi:10.1353/mpq.2002.0015

Banerjee, R., \& Yuill, N. (1999). Children's explanations for self-presentational behaviour. European Journal of Social Psychology, 29, 105-111. doi:10.1002/(SICI)10990992(199902)29:1<105::AID-EJSP910>3.0.CO;2-K

Bernard, S., Harris, P., Terrier, N., \& Clément, F. (2015). Children weigh the number of informants and perceptual uncertainty when identifying objects. Journal of Experimental Child Psychology, 136, 70-81. doi:10.1016/j.jecp.2015.03.009

Bernard, S., Proust, J., \& Clément, F. (2015). Four- to six-year-old children's sensitivity to reliability versus consensus in the endorsement of object labels. Child Development, 86 , 1112-1124. doi:10.1111/cdev.12366

Birch, S. A. J., Akmal, N., \& Frampton, K. L. (2010). Two-year-olds are vigilant of others' 
non-verbal cues to credibility. Developmental Science, 13, 363-369. doi:10.1111/j.14677687.2009.00906.x

Bond, R., \& Smith, P. B. (1996). Culture and conformity: A meta-analysis of studies using Asch's Line judgment task. Psychological Bulletin, 119, 111-137. doi:10.1037//00332909.119.1.111

Boseovski, J. J., \& Lee, K. (2008). Seeing the world through rose-colored glasses? Neglect of consensus information in young children's personality judgments. Social Development, $17,399-416$.

Boseovski, J. J., Marble, K. E., \& Hughes, C. (2017). Role of expertise, consensus, and informational valence in children's performance judgments. Social Development, 26, 445-465. doi:10.1111/sode.12205

Brosseau-Liard, P. E., Penney, D., \& Poulin-Dubois, D. (2015). Theory of mind selectively predicts preschoolers' knowledge-based selective word learning. British Journal of Developmental Psychology, 33, 464-475. doi:10.1111/bjdp.12107

Cialdini, R. B., \& Goldstein, N. J. (2004). Social influence: Compliance and conformity. Annual Review of Psychology, 55, 591-621. doi:10.1146/annurev.psych.55.090902.142015

Claidière, N., \& Whiten, A. (2012). Integrating the study of conformity and culture in humans and nonhuman animals. Psychological Bulletin, 138, 126-145. doi:10.1037/a0025868

Corriveau, K. H., Fusaro, M., \& Harris, P. L. (2009). Preschoolers prefer non-dissenters as informants. Psychological Science, 20, 372-377. doi:10.1111/j.1467-9280.2009.02291.x

Corriveau, K. H., \& Harris, P. L. (2010). Preschoolers (sometimes) defer to the majority in making simple perceptual judgments. Developmental Psychology, 46, 437-445. 
doi:10.1037/a0017553

Corriveau, K. H., Kim, E., Song, G., \& Harris, P. L. (2013). Young children's deference to a consensus varies by culture and judgment setting. Journal of Cognition and Culture, 13, 367-381. doi:10.1163/15685373-12342099

Deutsch, M., \& Gerard, H. B. (1955). Study of normative and informational influence upon individual judgment. Journal of Abnormal and Social Psychology, 51, 629-636.

Eaves, B. S., \& Shafto, P. (2012). Unifying pedagogical reasoning and epistemic trust. Advances in Child Development and Behavior, 43, 295-319. doi:10.1016/B978-0-12397919-3.00011-3

Einav, S. (2014). Does the majority always know best? Young children's flexible trust in majority opinion. PloS One, 9, e104585. doi:10.1371/journal.pone.0104585

Einav, S., \& Robinson, E. J. (2011). When being right is not enough: Four-year-olds distinguish knowledgeable informants from merely accurate informants. Psychological Science, 22, 1250-1253. doi:10.1177/0956797611416998

Fusaro, M., \& Harris, P. L. (2008). Children assess informant reliability using bystanders' non-verbal cues. Developmental Science, 11, 771-777. doi:10.1111/j.14677687.2008.00728.x

Goldman, A. I. (2001). Experts: Which ones should you trust? Philosophy and Phenomenological Research, 63, 85-110. doi:10.1111/j.1933-1592.2001.tb00093.x

Guerrero, S., Cascado, C., Sausa, M., \& Enesco, I. (2017). My teacher is wrong: Preschoolers' opposition to non-conventional statements. Early Childhood Research Quarterly, 39, 1-13. doi:10.1016/j.ecresq.2016.11.001

Harris, P. L. (2012). Trusting what you're told: How children learn from others. Cambridge, Mass.: Harvard University Press. 
Haun, D. B. M., Rekers, Y., \& Tomasello, M. (2012). Majority-biased transmission in chimpanzees and human children, but not orangutans. Current Biology, 22, 727-731. doi:10.1016/j.cub.2012.03.006

Haun, D. B. M., \& Tomasello, M. (2011). Conformity to peer pressure in preschool children. Child Development, 82, 1759-1767. doi:10.1111/j.1467-8624.2011.01666.x

Haun, D. B. M., Van Leeuwen, E. J. C., \& Edelson, M. G. (2013). Majority influence in children and other animals. Developmental Cognitive Neuroscience, 3, 61-71. doi:10.1016/j.den.2012.09.003

Herrmann, P. A., Legare, C. H., Harris, P. L., \& Whitehouse, H. (2013). Stick to the script: the effect of witnessing multiple actors on children's imitation. Cognition, 129, 536-43. doi:10.1016/j.cognition.2013.08.010

Heyman, G. D. (2014). Children's reasoning about deception: a cross-cultural perspective. In E. J. Robinson \& S. Einav (Eds.), Trust and Skepticism: Children's selective learning from testimony (pp. 83-95). London: Psychology Press.

Heyman, G. D., \& Legare, C. H. (2005). Children's evaluation of sources of information about traits. Developmental Psychology, 41, 636-647. doi:10.1037/0012-1649.41.4.636

Hu, J., Whalen, A., Buchsbaum, D., Griffiths, T., \& Xu, F. (2015). Can children balance the size of a majority with the quality of their information? In D.C. Noelle et al. (Ed.), Proceedings of the thirty-seventh annual conference of the cognitive science society (pp. 956-961). Austin, TX: Cognitive Science Society.

Jaswal, V. K., \& Malone, L. S. (2007). Turning believers into skeptics: 3-year-olds' sensitivity to cues to speaker credibility. Journal of Cognition and Development, 8, 263283. doi:10.1080/15248370701446392

Kelley, H. H. (1973). The processes of causal attribution. American Psychologist, 28, 107- 
128. doi:10.1037/h0034225

Koenig, M. A., \& Harris, P. L. (2005). Preschoolers mistrust ignorant and inaccurate speakers. Child Development, 76, 1261-1277. doi:10.1111/j.1467-8624.2005.00849.x

Lackey, J. (2013). Disagreement and belief dependence: Why numbers matter. In D. Christensen \& J. Lackey (Eds.), The Epistemology of Disagreement (pp. 243-266). Oxford: Oxford University Press. doi:10.1093/acprof:oso/9780199698370.003.0012

Lorenz, J., Rauhut, H., Schweitzer, F., \& Helbing, D. (2011). How social influence can undermine the wisdom of crowd effect. Proceedings of the National Academy of Sciences of the United States of America, 108, 9020-9025. doi:10.1073/pnas.1008636108

Lucas, A. J., Lewis, C., Pala, F. C., Wong, K., \& Berridge, D. (2013). Social-cognitive processes in preschoolers' selective trust: Three cultures compared. Developmental Psychology, 49, 579-590. doi:10.1037/a0029864

Miller, B. (2013). When is consensus knowledge based? Distinguishing shared knowledge from mere agreement. Synthese, 190, 1293-1316. doi:10.1007/s11229-012-0225-5

Miller, S. A. (2012). Theory of mind: Beyond the preschool years. Hove: Psychology Press.

Mills, C. M. (2013). Knowing when to doubt: Developing a critical stance when learning from others. Developmental Psychology, 49, 404-418. doi:10.1037/a0029500

Mills, C. M., \& Elashi, F. B. (2014). Children's skepticism: Developmental and individual differences in children's ability to detect and explain distorted claims. Journal of Experimental Child Psychology, 124, 1-17. doi:10.1016/j.jecp.2014.01.015

Mills, C. M., \& Keil, F. C. (2005). The development of cynicism. Psychological Science, 16, 385-390. doi:10.1111/j.0956-7976.2005.01545.x 
Mills, C. M., \& Keil, F. C. (2008). Children's developing notions of (im)partiality. Cognition, 107, 528-551. doi:10.1016/j.cognition.2007.11.003

Pasquini, E. S., Corriveau, K. H., Koenig, M. A., \& Harris, P. L. (2007). Preschoolers monitor the relative accuracy of informants. Developmental Psychology, 43, 1216-1226.

Peirce, J. W. (2007). PsychoPy - Psychophysics software in Python. Journal of Neuroscience Methods, 162, 8-13. doi:10.1016/j.jneumeth.2006.11.017

Robinson, E. J., \& Einav, S. (2014). Trust and skepticism: Children's selective learning from testimony. London: Psychology Press. doi:10.4324/9781315849362

Sabbagh, M. A., \& Baldwin, D. A. (2001). Learning words from knowledgeable versus ignorant speakers: Links between preschoolers' theory of mind and semantic development. Child Development, 72, 1054-1070.

Schillaci, R. S., \& Kelemen, D. (2014). Children's conformity when acquiring novel conventions: The case of artifacts. Journal of Cognition and Development, 15, 569-583. doi:10.1080/15248372.2013.784973

Schneider, D. M., \& Watkins, M. J. (1996). Response conformity in recognition testing. Psychonomic Bulletin \& Review, 3, 481-485. doi:10.3758/BF03214550

Sperber, D., Clément, F., Heintz, C., Mascaro, O., Mercier, H., Origgi, G., \& Wilson, D. (2010). Epistemic vigilance. Mind and Language, 25, 359-393. doi:10.1111/j.14680017.2010.01394.x

Wilks, M., Collier-Baker, E., \& Nielsen, M. (2015). Preschool children favor copying a successful individual over an unsuccessful group. Developmental Science, 18, 10141024. doi:10.1111/desc. 12274 
Table 1

Percentage of participants, by age group, who predominantly sided with the Independent consensus (IC), the Non-independent consensus (NIC) or were mixed.

\begin{tabular}{|c|c|c|c|}
\hline Age & 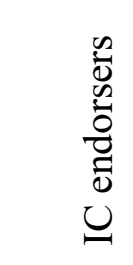 & $\begin{array}{l}\vec{D} \\
\stackrel{x}{\Sigma}\end{array}$ & 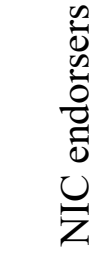 \\
\hline 5-year-olds $(n=27)$ & 14.8 & 33.3 & 51.9 \\
\hline 6-year-olds $(n=32)$ & 18.9 & 50.0 & 31.3 \\
\hline $8-9$ year-olds $(\mathrm{n}=30)$ & 66.7 & 10.0 & 23.3 \\
\hline
\end{tabular}



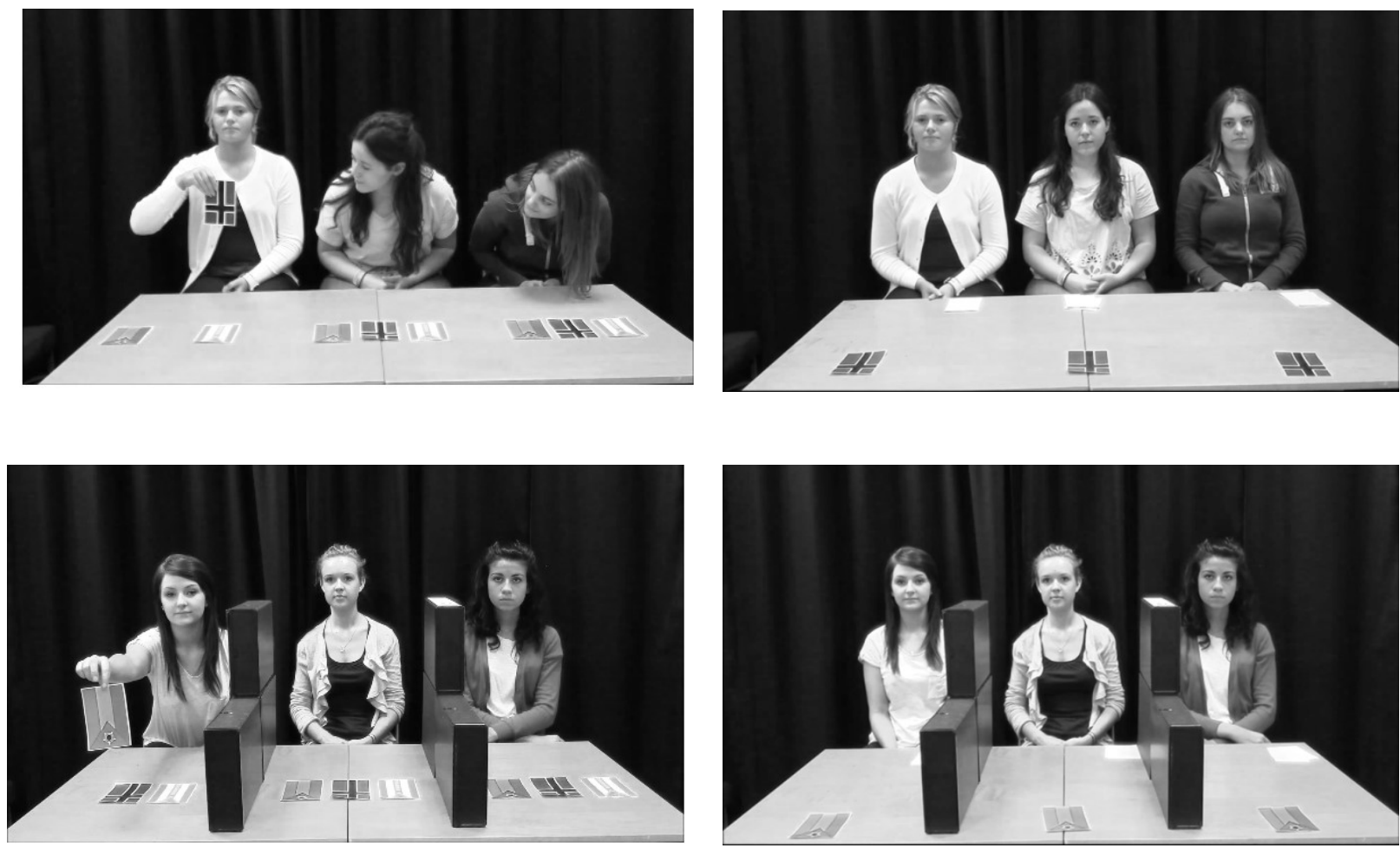

Figure 1. Examples of the NIC (top panel) and IC (bottom panel) informant groups at time of first informant's response (left) and with final screen shots of all responses (right). 


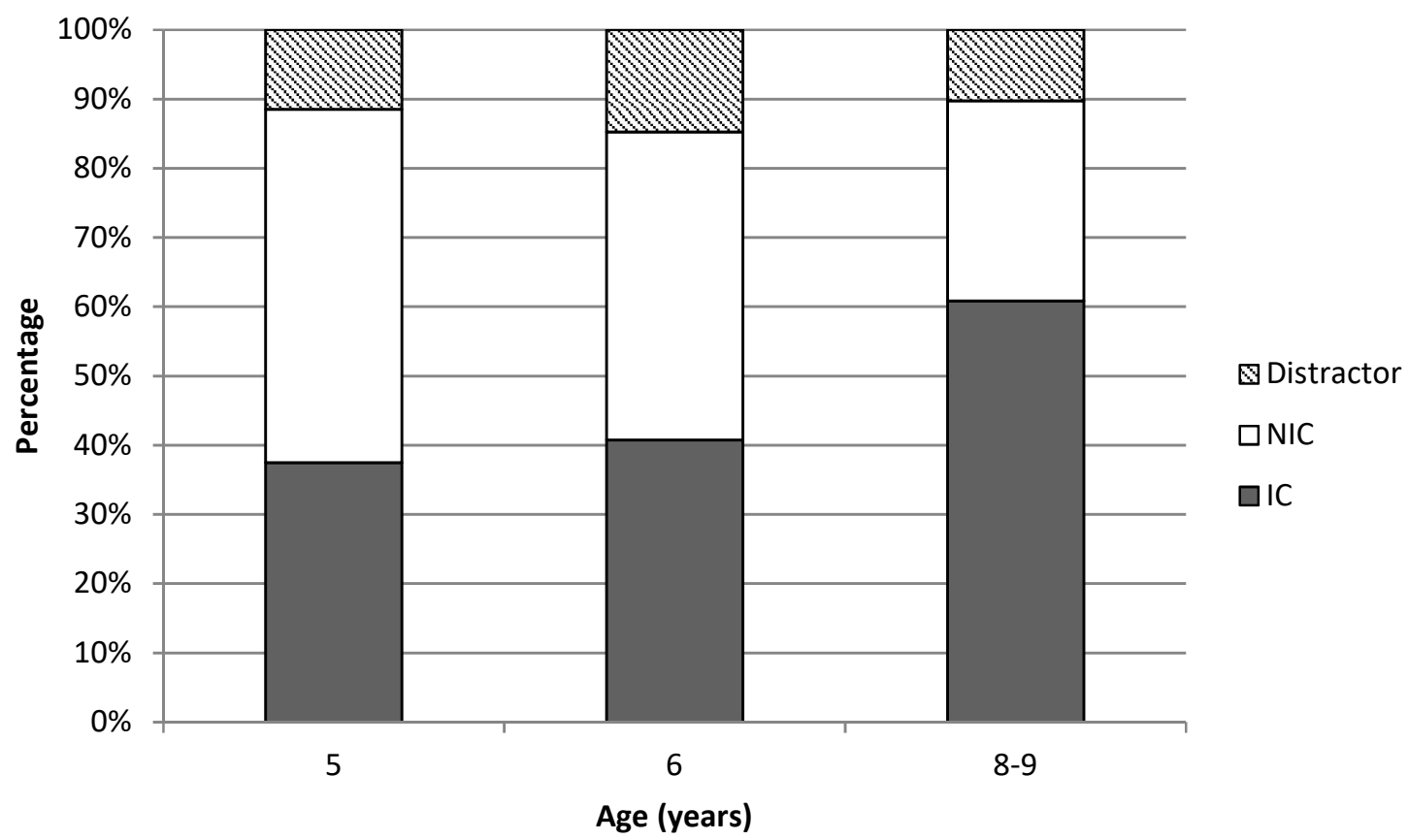

Figure 2. Percentage of choices linked to the independent consensus (IC), non-independent consensus (NIC), and distractor for each age group. 


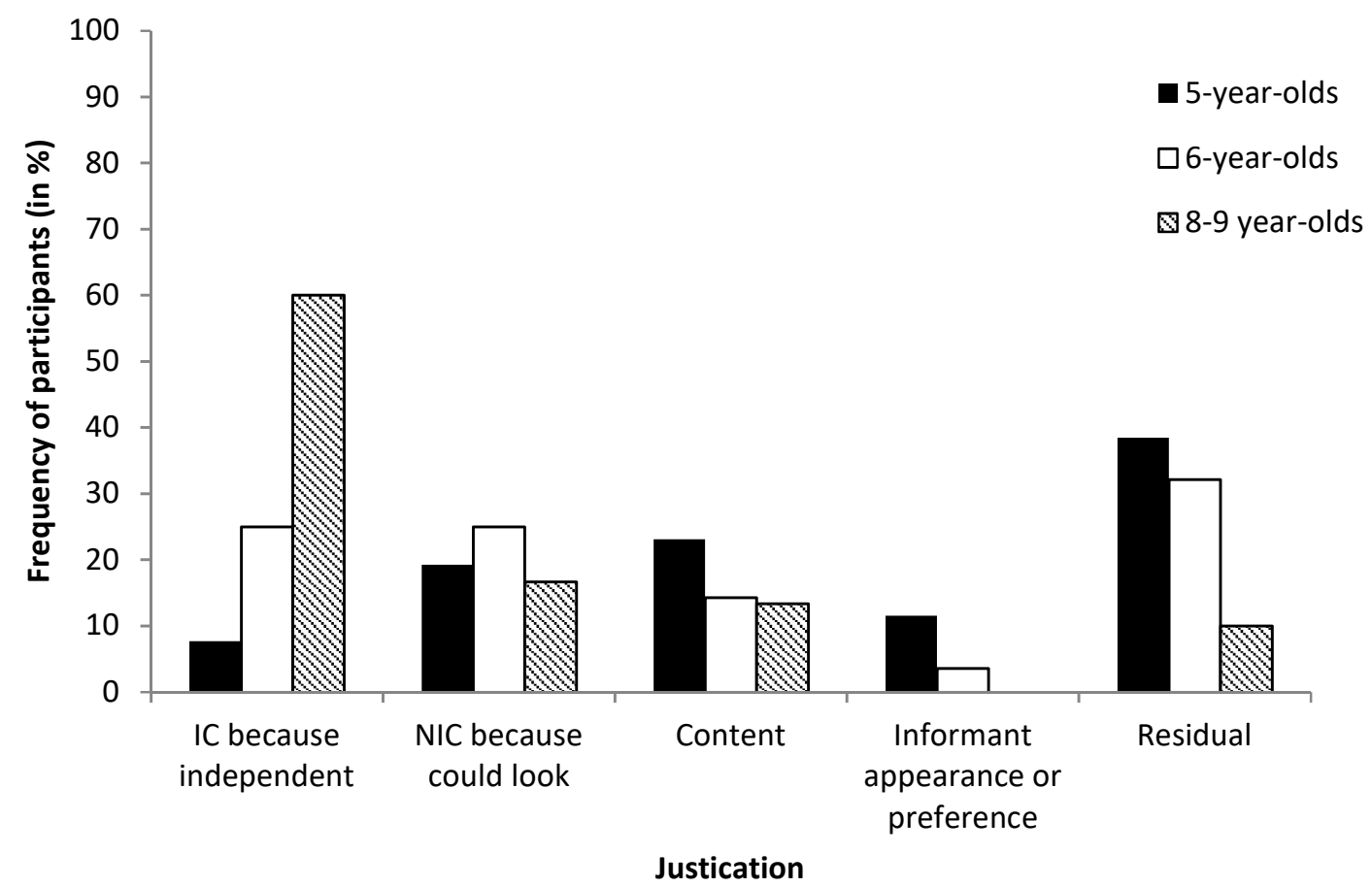

Figure 3. Frequency distributions of justifications for why children believed a particular group over the other, by age group. 